\title{
Transoral Flexible Endoscopic Therapy of Zenker's Diverticulum
}

\author{
Ryan Law Todd H. Baron \\ Division of Gastroenterology and Hepatology, Mayo Clinic, Rochester, Minn., USA
}

\section{Dear Sir,}

We read with interest the excellent article on surgical treatment of Zenker's diverticulum (ZD) by Yuan et al. [1]. However, their citations on flexible endoscopic management of ZD are lacking. They cite only two articles from the initial description of flexible therapy of ZD from nearly 20 years ago. Since those two original descriptions, over 15 series involving more than 600 patients have been published [2-4]. Overall, the results of flexible therapy compare favorably to rigid endoscopic therapy. Indeed, one article retrospectively compared flexible and rigid endoscopic therapy showing similar outcomes [5]. Flexible endoscopic procedures are usually performed by gastroenterologists or surgical endoscopists in the endoscopy suite, whereas rigid endoscopic procedures are performed by surgeons in the operating room. The advantages of a flexible endoscopic approach rest in a wider visual field and flexibility and smaller endoscope diameter, which are especially useful for patients with poor neck extension and/or limited jaw retraction. It can also be performed without the use of general anesthesia in many instances.

A transoral flexible endoscopic approach successfully reduces cricopharyngeal sphincter pressure [6]. The septum can be divided with a variety of cutting instruments and accessories.

It is unknown whether a transoral flexible endoscopic approach will show longterm results compared to rigid surgical therapy for long-term relief of symptoms. In one recent study in which $94 \%$ of patients underwent transoral rigid endoscopic therapy, durable relief of symptoms was noted in only $\sim 40 \%$ of the cases (including recurrences) [7]. One limitation of the currently available flexible endoscopic data is the paucity of quality patient follow-up. In evaluation of the available studies, nearly one third demonstrate inadequate postprocedure follow-up. However, with improvements in techniques and technologies, we believe a complete myotomy can be achieved safely and effectively using a flexible transoral approach.

\section{References}

1 Yuan Y, Zhao YF, Hu Y, Chen LQ: Surgical treatment of Zenker's diverticulum. Dig Surg 2013;30:214-225.

-2 Katzka DA, Baron TH: Transoral flexible endoscopic therapy of Zenker's diverticulum: is it time for gastroenterologists to stick their necks out? Gastrointest Endosc 2013;77:708-710.

3 Ferreira LE, Simmons DT, Baron TH: Zenker's diverticula: pathophysiology, clinical presentation, and flexible endoscopic management. Dis Esophagus 2008;21:1-8.
4 Dzeletovic I, Ekbom DC, Baron TH: Flexible endoscopic and surgical management of Zenker's diverticulum. Expert Rev Gastroenterol Hepatol 2012;6:449-465, quiz 466.

$\checkmark 5$ Repici A, Pagano N, Fumagalli U, Peracchia A, Narne S, Malesci A, Rosati R: Transoral treatment of Zenker diverticulum: flexible endoscopy versus endoscopic stapling. A retrospective comparison of outcomes. Dis Esophagus 2011;24:235-239.
The other minor comment relates to table 5 by Yuan et al. [1] in which they state that flexible endoscopic therapy is unsuitable for both small and large diverticula. Having treated more than 50 patients at our institution, we can assert that flexible endoscopic therapy can be used for all sizes of diverticula, though small diverticula are more technically difficult to treat. A previous compilation of available studies by Ferreira et al. [3] has shown that ZD of various sizes can be treated, ranging from 2 to 12 $\mathrm{cm}$, with a high rate of clinical success.

Ideally, head-to-head comparative trials of transoral flexible endoscopic and rigid endoscopic myotomy are needed to determine the optimal approach to patients with ZD.

\section{Disclosure Statement}

None.

\section{KARGER}

E-Mail karger@karger.com www.karger.com/dsu (c) 2013 S. Karger AG, Basel

0253-4886/13/0306-0393\$38.00/0
Todd H. Baron, MD

Division of Gastroenterology and Hepatology, Mayo Clinic 200 First Street SW

Rochester, MN 55905 (USA)

E-Mail baron.todd@ mayo.edu
Ishioka S, Felix VN, Sakai P, Melo J, Pinotti HW: Manometric study of the upper esophageal sphincter before and after endoscopic management of Zenker's diverticulum. Hepatogastroenterology 1995;42:628-632.

7 Koch M, Mantsopoulos K, Velegrakis S, Iro, Zenk J: Endoscopic laser-assisted diverticulotomy versus open surgical approach in the treatment of Zenker's diverticulum. Laryngoscope 2011;121:2090-2094. 